DOI: $10.5007 / 2175-7941.2012 v 29 n e s p 1 p 390$

\title{
O QUE OS PROFESSORES PENSAM SOBRE O PION, O PORTAL SBF DE ENSINO E DIVULGAÇÃO DA FÍSICA
}

Felipe Moron Escanhoela

Instituto Federal de Santa Catarina - IF-SC

Canoinhas - SC

Nelson Studart

Departamento de Física - UFSCar

São Carlos - SP

\section{Resumo}

O Pion, Portal SBF de Ensino e Divulgação da Física $(<h t t p: / / w w w$.pion.org.br $>$ ), disponibiliza diversos objetos de aprendizagem relacionados à física e ao ensino desta ciência, visando o público em geral e particularmente os professores de física. Inserido em um contexto em que há um grande número de recursos publicados em portais na internet, mas ainda com poucos trabalhos que tenham avaliado a efetividade educacional do uso destes portais no ensino de física no Brasil, o Pion foi desenvolvido por três anos sem uma avaliação de sua usabilidade e sua real utilização pelo público, bem como um levantamento do perfil de seus usuários. Este trabalho relata a realização de uma avaliação dessa natureza, que teve como objetivo gerar dados que orientem a implementação de novas funcionalidades, a inserção de conteúdos e outras ações para correção de problemas do portal. Para isso, questões de múltipla escolha, além de uma questão aberta, foram

\footnotetext{
${ }^{+}$What teachers think about Pion, the web portal of the Brazilian Physical Society (SBF) for Physics teaching and dissemination

* Recebido: fevereiro de 2012.

Aceito: abril de 2012.
} 
enviadas em formulário on-line, via e-mail, para os usuários cadastrados no sistema do portal. As respostas fechadas foram avaliadas seguindo-se um modelo de escala de Likert e as opiniões expressas na questão aberta foram classificadas segundo categorias criadas a posteriori. A pesquisa levou à conclusão de que o Pion está bem estruturado quanto à sua usabilidade e cumpre o papel de auxiliar o professor em sua busca por informações relevantes à prática docente, embora ainda precise de melhorias em aspectos relacionados à interação com o público e à interatividade de modo geral.

Palavras-chave: Portal de educação. Ensino de Física. Informática na educação. Professor de Física. Objeto de aprendizagem. Usabilidade de portal de internet.

\begin{abstract}
Pion, the web portal of the Brazilian Physical Society (SBF) for Physics teaching and dissemination (<http://www.pion.org.br>), provides to the public at large and particularly Physics teachers, a collection of learning objects related to physics and its teaching. In a context in which there is a large number of resources published on Internet portals, but still few studies that have evaluated the educational effectiveness of the use of these portals in Physics teaching in Brazil, Pion was developed for three years without an evaluation on its usability and use by the public, as well as a gathering of the profile of its users. This work reports the achievement of one such evaluation research, that aimed to generate data to guide the implementation of new features, the inclusion of content and other actions to correct the problems of the portal. Thus, an on-line form with multiple-choice questions and one open question were sent by e-mail to all registered users of the portal. The closed responses were evaluated in line with a Likert scale model and the views expressed in the open question were classified according to afterwards created categories. The research led to the conclusion that Pion is well structured concerning its usability and fulfills the role of assisting the teacher in their search for relevant information to teaching practice, although it still needs for improvement in aspects related to interaction with the public and the interactivity in general.
\end{abstract}


Keywords: Education web portal. Physics teaching. Informatics in education. Physics teacher. Learning objects. Web portal usability.

\section{Introdução}

O Pion, Portal SBF de Ensino e Divulgação da Física ${ }^{l}$, foi desenvolvido pela Sociedade Brasileira de Física, SBF, com o apoio do Conselho Nacional de Desenvolvimento Científico e Tecnológico, CNPq, que financiou o portal por meio de editais do MCT abertos para projetos de divulgação científica. O objetivo do portal é disponibilizar para estudantes, interessados e, principalmente, professores, um acervo de materiais didáticos, vídeos, fotografias, ilustrações, simulações, entre outros recursos relacionados à física e ao ensino desta ciência, de forma a auxiliar o trabalho docente, servir de base para pesquisas escolares e divulgar a física para o grande público.

Todos esses recursos podem ser classificados, de maneira geral, como Objetos de Aprendizagem. Apesar de não haver consenso na literatura sobre o termo, o significado de Objetos de Aprendizagem usado aqui é o apresentado por Studart (2011):

[...] considero que os OAs são objetos digitais disponíveis na web projetados especificamente com objetivos educacionais que podem ser utilizados, reutilizados, referenciados e controlados para criar ou apoiar situações de aprendizagem para uma audiência identificada. Meu interesse em OAs no contexto do ensino de ciências concentra-se em audiovisuais, vídeos, animações, simulações e textos multimídia.

Os responsáveis pela concepção do portal foram o jornalista Francisco Rolfsen Belda, profissionais da MZO Interativa ${ }^{2}$, desenvolvedora de software com sede em São Carlos, SP, coordenados pelo diretor da empresa, Paulo Roberto Mascarenhas, e o segundo autor, orientador da pesquisa de mestrado que deu origem a este artigo.

\footnotetext{
${ }^{1} \mathrm{O}$ Pion pode ser acessado nos endereços $<$ www.pion.org.br $>$ e $<$ www.pion.sbfisica.org.br>.

$2<$ www.mzo.com.br>. A MZO participou como desenvolvedora do Content Management System, CMS, ferramenta de gerenciamento de conteúdo on-line que deu suporte ao portal. O CMS escolhido foi o eZ Publish, que permitiu as adaptações necessárias.
} 
Baseado nas ideias de interatividade e colaboração, o projeto permite a participação dos usuários na geração ou indicação de conteúdos para o portal, disponibilizando, para isso, formulários para envio de diversos tipos de mídia. Além disso, o Fórum do portal pode ampliar o relacionamento entre os estudantes, os físicos e os professores de Ensino Médio, constituindo-se em um espaço para discussões, críticas, esclarecimento de dúvidas e troca de experiências. Esses recursos refletem uma tendência de desenvolvimento de sites educativos baseados no conceito de Web 2.0 ${ }^{3}$. Como anunciam Isontani et. al (2009), "no contexto educacional, a interação contínua entre aprendiz-aprendiz e aprendiz-conteúdo, e a possibilidade de argumentar e compreender diferentes pontos de vista é um dos melhores cenários para uma aprendizagem mais rica e duradoura".

Em junho de 2008, após receber aproximadamente 600 sugestões de nomes, o Portal foi batizado como Pion. Seu nome é uma homenagem ao físico brasileiro César Lattes, codescobridor da partícula elementar conhecida por Méson pi ou Pion. Seu lançamento oficial aconteceu em julho de 2008, durante a reunião anual da SBPC.

Atualmente, o Pion recebe uma média de aproximadamente 25.000 visitas por mês. Além disso, o portal conta com mais de 2.000 internautas cadastrados por meio de formulário on-line. O cadastro é necessário para participação no Fórum e envio de material colaborativo; também constitui a base de endereços eletrônicos para envio da newsletter.

As seguintes seções podem ser acessadas no portal: Artigos, Links, Destaques, Desafios, Eventos, Multimídia, Material didático, Enquetes, Fórum, Físicos do Brasil e Blog, além das ferramentas de Fale Conosco, Mapa do Site, Login, Busca e Newsletter ${ }^{4}$.

\footnotetext{
3 "O termo Web 2.0 é utilizado para descrever a segunda geração da World Wide Web, WWW, tendência que reforça o conceito de troca de informações e colaboração dos internautas com sites e serviços virtuais. Trata-se de uma internet mais colaborativa, baseada em plataformas (softwares) que permitem aos usuários compartilhar informações e ter uma atuação mais ativa e participativa" (HAGUENAUER et al., 2007).

A atualização do conteúdo destas seções está temporariamente suspensa, pois o portal passa por uma fase de transição - mudança de editor.
} 


\section{Pesquisa de avaliação}

Inserido em um contexto em que há um grande número de recursos publicados em portais na internet 5 , mas ainda com poucos trabalhos que tenham avaliado a efetividade educacional do uso destes portais no ensino de física no Brasil, o Pion foi desenvolvido por três anos sem uma avaliação de sua usabilidade e sua real utilização pelo público, bem como um levantamento do perfil de seus usuários.

Com o objetivo de avaliar o Pion com relação a esses aspectos, em janeiro de 2011 foi realizada uma pesquisa de opinião entre seus usuários. A pesquisa buscou responder à questão sobre como professores, alunos e o público em geral interagem com o portal.

Assim, procurou-se contemplar no questionário (ver anexo A) perguntas referentes a três aspectos principais:

1) Facilidade com que o usuário encontra as informações - diante da proliferação de OAs na internet, selecionar e explorar os recursos oferecidos por cada um deles para encontrar a melhor opção de trabalho não é tarefa fácil e pode demandar muito tempo, recurso precioso para os profissionais da educação. Nesse sentido, o Pion [como um portal que disponibiliza diferentes tipos de OAs de forma seletiva e organizada] auxilia o professor para que este desempenhe o seu papel em sala de aula?

2) Forma como as informações são apresentadas no portal - os signos utilizados são adequados ao público?

3) Grau de interatividade do internauta respondente com os conteúdos do portal e com outros internautas - o Pion segue a tendência da Web 2.0? Pode ser

\footnotetext{
5 Alguns exemplos de repositórios internacionais de OAs de física são: Interactive Science Simulations, PhET $(<\mathrm{http}: / /$ phet.colorado.edu $>$ ); comPADRE - Physics and Astronomy Education Communities (<http://compadre.org $>$ ); Paul Falstad's Home Page $(<$ http://www.falstad.com/ $>)$; Physics 2000! $<$ http://www.colorado.edu/physics/2000/index.pl $>$ ) e IOP $\quad-\quad$ Physics.Org $(<$ http://www.physics.org/>). No Brasil, há dois grandes projetos de portais educacionais, desenvolvidos pelo Ministério da Educação, MEC: o Banco Internacional de Objetos Educacionais, BIOE (<http://objetoseducacionais.mec.gov.br/ $>$ ) e o Portal do Professor $(<\mathrm{http}: / /$ portaldoprofessor.mec.gov.br $>)$. Também vale a pena citar, seja por seu pioneirismo, seja pela qualidade apresentada, os seguintes portais: Núcleo de Construção de Objetos de Aprendizagem, NOA ( $<$ http://www.fisica.ufpb.br/ romero/objetosaprendizagem/index.html $>$ ), Laboratório Didático Virtual, LabVirt $\quad(<\mathrm{http}: / /$ www.labvirt.futuro.usp.br/>), Pontociência $(<\mathrm{http}: / /$ www.pontociencia.org.br/ $>)$, Laboratório Virtual da Estação Ciência $(<\mathrm{http}: / /$ www.ideiasnacaixa.com/laboratoriovirtual/>) e Ciência à mão (<http://www.cienciamao.if.usp.br $>$ ).
} 
considerado uma ferramenta de auxílio à interação social, como a defendida pelo pensador Lev Vygotsky? É comum encontrar artigos que relacionam a interação social proporcionada por ambientes virtuais de aprendizagem com as ideias de Vygotsky (1991). Um exemplo é o estudo realizado por Passerino e Santarosa (2002), que analisa um estudo desenvolvido a partir de um ambiente telemático:

$O A W^{6}$ se comporta como uma verdadeira ferramenta cognitiva e semiótica, ao suportar a comunicação não apenas textual, mas também visual e moto$\mathrm{ra}$, tornando-se um instrumento de mediação, que possibilita a interação entre sujeitos e objetos e entre sujeitos e sujeitos. Recordemos que, para Vygotsky, esta interação amplia a ZDP [zona de desenvolvimento proximal], antecipando os processos de desenvolvimento, que passam de um processo social para o individual pela internalização.

Também foram feitas questões de caráter mais técnico, com o objetivo de avaliar o funcionamento estrutural do sistema e dar parâmetros para futuras ações de melhoria.

\section{Metodologia}

Como a fonte de informações da avaliação é constituída basicamente de respostas a perguntas opinativas, apresentadas em um questionário do tipo survey com uma pergunta aberta -, o trabalho está mais próximo da pesquisa quantitativa. Entretanto, os métodos qualitativo e quantitativo não são mutuamente excludentes. Para Flick (2009),

Muitos questionários incluem perguntas abertas ou de texto livre, o que, em alguns contextos, já se encontra definido como pesquisa qualitativa, muito embora dificilmente qualquer princípio metodológico da pesquisa qualitativa seja incorporado com a utilização dessas questões. Mais uma vez não se trata de uma combinação explícita dessas duas formas de pesquisa, mas sim uma tentativa de assimilar uma tendência.

Assim, optou-se por se fazer uma integração entre os dois métodos (id. ibid., p. 42-44), em um plano em que as duas estratégias são adotadas paralelamente, de modo que a resposta à pergunta em aberto forneça bases para uma melhor

\footnotetext{
${ }^{6}$ "O Active Worlds (AW) é um ambiente híbrido que mistura recursos de Internet com ambientes 3D de Realidade Virtual não imersiva" (PASSERINO; SANTAROSA, 2002).
} 
interpretação dos números gerados com a parte quantitativa. Esse tipo de integração é baseado em uma forma de combinação entre as pesquisas qualitativa e quantitativa proposta por Miles e Huberman (1994 apud FLICK, 2009, p. 43).

A análise quantitativa tem como base as escalas Likert, usadas nas questões opinativas - a maior parte das questões apresentou cinco alternativas, representando diferentes níveis de intensidade para classificação de determinadas características ou funcionalidades do portal. Apesar de bastante próximas do modelo de Likert, as questões não apresentaram níveis de "concordância" e "discordância", mas rótulos bipolares, como "Totalmente ineficazes" / "Totalmente eficazes". Nesse sentido, pode-se dizer que o questionário também faz uso do modelo de escala de diferencial semântico (MALHOTRA, 2001).

Para a análise dos dados obtidos com as escalas tipo Likert, foram calculados os rankings médios nas questões, segundo o modelo exemplificado por Oliveira (2005), que usa a média ponderada dos valores atribuídos pelos respondentes.

Finalmente, as respostas à questão aberta foram reunidas em categorias criadas a posteriori, ou, conforme classifica Bardin (1977), partindo "dos elementos particulares" e reagrupando-os "progressivamente por aproximação de elementos contíguos, para, no final deste procedimento", atribuir "um título à categoria". A fim de se cruzar duas dimensões de análise, optou-se por se criar uma grade de análise $^{7}$ (id. ibid.).

Entre os 1864 destinatários, 137 usuários responderam à pesquisa. Isso representa 7,4\% do total. De acordo com Guerra (2006), em uma amostra por homogeneização, escolhida quando se quer estudar um determinado grupo homogêneo - neste caso, os usuários do Pion, que, certamente, têm características e interesses em comum -, "é difícil prever o número de entrevistas a realizar. (...) A maioria dos autores considera que a saturação ${ }^{8}$ está presente a partir de 30 a 50 entrevistas, mas, neste tipo de amostragem, dependendo da definição de homogeneidade, poderá ser menos." Desse modo, levando em conta o aumento da incerteza próprio da aplicação de questionários on-line ${ }^{9}, 137$ parece ser um número significativo para compor o universo amostral dos cadastrados.

\footnotetext{
7 "Grelha de análise", no original.

${ }^{8}$ Para Glaser e Strauss, "a saturação significa que não estão sendo encontrados dados adicionais por meio dos quais o sociólogo possa desenvolver as propriedades da categoria" (1967, p.61 apud FLICK, 2009, p.121).

Flick (2009) destaca que a utilização da internet facilita muitas coisas em um estudo, mas também que "uma troca de e-mails é diferente de perguntar e receber respostas pessoalmen-
} 


\section{Procedimento}

O questionário enviado aos internautas está dividido em cinco seções. A primeira delas, "Perfil do internauta", teve como objetivo fazer o levantamento do perfil do usuário do Pion que respondeu às questões. Inclui questões sobre sexo, idade, cidade de moradia e ocupação, além de campos para o nome e o e-mail do internauta - a obrigatoriedade do preenchimento desses últimos dados, se, por um lado, pode ter inibido a participação do público, por outro lado, serviu como uma forma de aumentar a credibilidade das respostas, já que a pesquisa foi realizada integralmente em ambiente on-line.

A segunda seção, "Usabilidade", foi baseada nas heurísticas ${ }^{10}$ para avaliação de usabilidade de portais corporativos descritas por Dias (2001). Como o público não conhece necessariamente os jargões técnicos desse tipo de avaliação, foram feitas simplificações das heurísticas para elaboração das questões. Além disso, um formulário muito detalhado poderia inibir ainda mais a participação dos usuários.

Na terceira seção, "utilização", pretendeu-se levantar informações a respeito da efetiva utilização do portal pelos usuários. Ela abrange questões sobre frequência de acesso, finalidade de acesso, tipo de material acessado e áreas de interesse.

A quarta seção é composta por uma questão referente à satisfação do usuário quanto à busca de informações no Pion.

A quinta seção é composta por uma questão aberta, que foi proposta com o objetivo de auxiliar na interpretação dos dados levantados nas questões anteriores, já que dá a oportunidade ao usuário de escrever críticas, elogios e sugestões sobre o portal: "Use este espaço para escrever críticas, elogios e sugestões ao Pion." A partir da leitura das respostas, foram criadas as seguintes dimensões e respectivas categorias:

te. (...) pessoas acessíveis na Web não esperam necessariamente fazer parte de um estudo. Os problemas de autenticidade e de contextualização resultam do anonimato dos participantes. Os Web sites desaparecem ou modificam-se, etc.'

10

O termo "heurística" é usado, aqui, com o sentido de "princípio geral", que é o adotado por Dias (2001) em seus métodos de avaliação de usabilidade de portais corporativos. Dessa forma, o significado do termo se aproxima do adotado pela ciência da computação: "um conjunto de regras e métodos que conduzem à descoberta, à invenção e à resolução de problemas" (HEURÍSTICA, 2011). 
1. De valor: dividida nas categorias "Negativo" (-), "Neutro" (n) e "Positivo" (+). Esta dimensão contempla os juízos de valor feitos pelos usuários com relação ao Pion. Como a questão incentiva "críticas, elogios e sugestões", respostas que levantavam problemas no portal e sugestões (que indicam pontos a serem melhorados) foram classificadas como negativas. Elogios entraram na categoria "Positivo". Comentários livres de juízos de valor ou muito vagos foram classificados como neutros.

2. De tema: dividida em "Fora do escopo" (1), "Geral" (2), "Conteúdo" (3), "Problemas técnicos" (4), "Layout e organização da informação" (5), "Divulgação do Portal" (6), "Interação com/entre professores e funcionalidades" (7), "Desenvolvimento/divulgação da ciência" (8), "Apoio ao ensino/professor/aluno" (9) e "Linguagem" (10).

Como muitas respostas poderiam se encaixar em mais de uma categoria, optou-se, para fins de classificação, por separá-las nos trechos correspondentes. A resposta reproduzida a seguir é um exemplo de conteúdo com mais de uma classificação.

Divulgar mais e criar um espaço de interação entre professores. Newsletter das últimas notícias publicadas. Maior interação e 'aproximação' da SBF com os professores que realmente motivam e continuam com toda dificuldade que a ciência tem, como a divulgar ciências e principalmente o Ensino de Física.

Na dimensão 1 (de valor), essa resposta entrou na categoria "Negativo", já que traz sugestões. Na dimensão 2 (de tema), entrou nas categorias "Divulgação do Portal", "Interação com/entre professores e funcionalidades" e "Desenvolvimento/divulgação da ciência".

\section{Resultados e discussão}

\section{V.1 Perfil do usuário respondente}

Com base nos dados coletados, pode-se traçar um perfil do usuário cadastrado no Pion que respondeu à pesquisa: professor de Física do Ensino Médio do sexo masculino, com idade entre 21 e 50 anos e residente na região sudeste. 


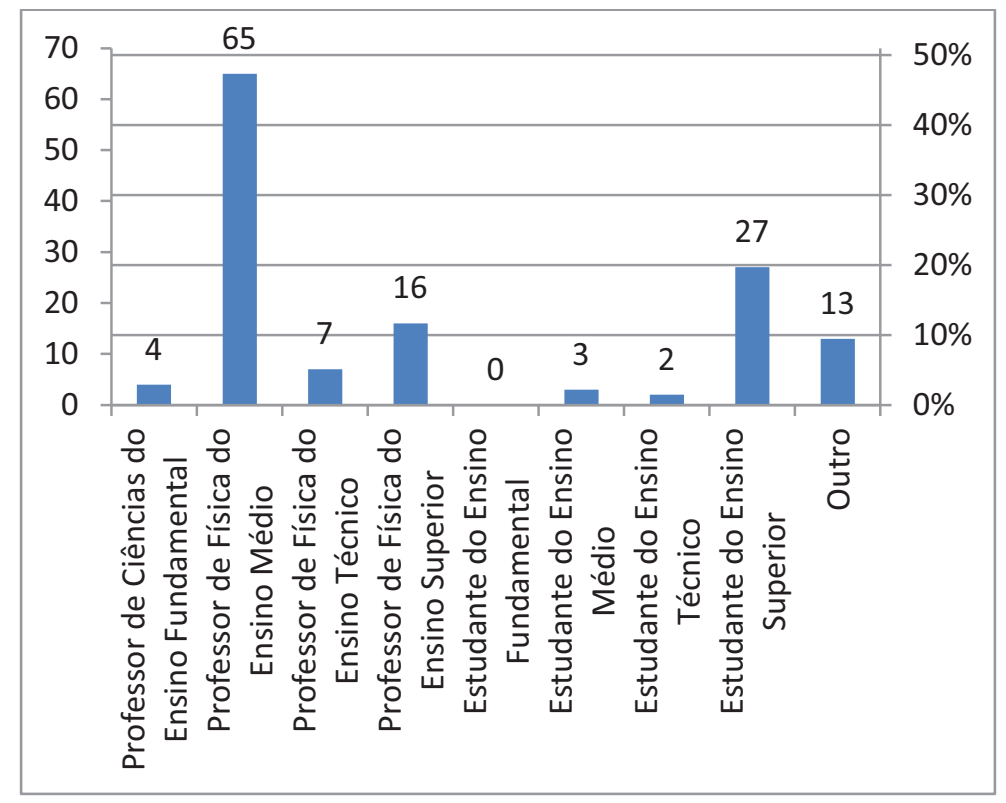

Fig. 1 - Número de internautas usuários do Pion que responderam ao formulário de avaliação, segundo ocupação $(N=137)$.

Este resultado reflete o perfil do professor de física de um modo geral. Ficando apenas no caso dos professores de física do EM, que representam 47\% da amostra, pode-se fazer uma comparação dos dados destes respondentes com as informações fornecidas por Teixeira, Júnior e Golfette (2004) em seu levantamento do perfil dos professores de física do EM no estado de São Paulo: na pesquisa sobre os usuários do Pion, $14 \%$ desses profissionais são do sexo feminino - contra $86 \%$ do masculino - e $85 \%$ estão na faixa dos 20 aos 50 anos. Os autores da pesquisa feita em SP chegam a $17 \%$ e $83 \%$ no caso dos gêneros e $68 \%$ para uma faixa etária entre 20 e 45 anos.

É interessante notar, também, a significativa participação de estudantes do ensino superior ( $20 \%$ dos respondentes). O questionário não solicita a especificação do curso em que estão inseridos, mas, com base nos dados levantados (Fig. 1) e na proposta do portal, é possível supor que estes estudantes são, em sua maioria, alunos de cursos de licenciatura em física e/ou ciências exatas. 


\section{V.2 Usabilidade}

Para a questão "Em uma escala que vai de 1 (totalmente ineficazes) a 5 (totalmente eficazes), como você avalia as orientações presentes no Pion com relação à página em que você se encontra, ao caminho que o levou até essa página e às suas opções de saída - links, menus, títulos etc.?”, o ranking médio (RM) calculado foi de:

$$
((2 * 1)+(4 * 2)+(33 * 3)+(59 * 4)+(39 * 5)) / 137 \approx 4
$$

O valor do RM está entre o número que indica a eficácia média (3) e o que indica a total eficácia das orientações (5), o que pode ser entendido como uma avaliação positiva, embora mostre que o fator avaliado pode ser melhorado.

As orientações de navegação são fundamentais para que o usuário encontre o que procura e permaneça visitando o portal. Para Dias (2001), "em virtude da forma hipertextual, não-linear de interação e da quantidade de páginas disponíveis na Internet, um dos maiores problemas identificados em testes com usuários é sua desorientação".

Para a questão "Em uma escala que vai de 1 (muito difíceis) a 5 (muito fáceis), como você avalia a leitura e a compreensão do conteúdo disponível no Pion? Leve em conta a legibilidade, a estética e a quantidade de informação por página.", o ranking médio calculado foi de:

$$
((1 * 1)+(6 * 2)+(31 * 3)+(64 * 4)+(35 * 5)) / 137 \approx \mathbf{4 , 0}
$$

O valor do RM está entre o número que indica a neutralidade (3) e o que indica a extrema facilidade de leitura (5). A avaliação desse resultado pode ser vista como positiva, embora a opção "Muito fáceis" possa ser entendida como um indicativo de inadequação da linguagem ao público (mensagens com elevada redundância ${ }^{11}$ ).

Um grande mérito do Pion é não depender de publicidade. Uma das recomendações de Dias (2001) para a garantia de um bom projeto estético e uma equilibrada densidade de informações é "não usar propaganda".

Para a questão "Em uma escala que vai de 1 (totalmente insatisfeito) a 5 (totalmente satisfeito), como você avalia sua satisfação com relação ao controle detido por você sobre o processamento de suas ações pelo portal, levando em conta

\footnotetext{
${ }^{11} \mathrm{O}$ termo redundância refere-se, na Teoria da Informação, ao oposto de Entropia em uma situação. Nas palavras de Littlejohn (1982, p.156), "em termos qualitativos, a redundância é a proporção de uma situação que é previsível; é uma medida da certeza. Numa relação, se uma alternativa resulta de outra, ela é previsível e, por conseguinte, redundante. Em suma, redundância é o grau de previsibilidade numa situação ou mensagem".
} 
o atendimento a suas solicitações e expectativas?", o ranking médio calculado foi de:

$$
((1 * 1)+(9 * 2)+(26 * 3)+(59 * 4)+(42 * 5)) / 137 \approx 4
$$

$\mathrm{O}$ valor do RM está entre o número que indica a satisfação média (3) e o que indica a total satisfação (5). O resultado pode ser avaliado positivamente, embora sugira que melhorias possam ser realizadas no que se refere ao controle detido pelo usuário.

Para a questão "Em uma escala que vai de 1 (inexistente) a 5 (muito grande), como você avalia a capacidade do Pion em se adaptar ao contexto e às necessidades e preferências do internauta, em função da diversidade de tipos de usuários do portal? Leve em conta a flexibilidade de sua interface para a realização da mesma tarefa de diferentes maneiras.", o ranking médio calculado foi de:

$$
((2 * 1)+(7 * 2)+(38 * 3)+(61 * 4)+(29 * 5)) / 137 \approx 4
$$

O valor do RM está entre o número que indica a capacidade média (3) e o que indica uma grande capacidade (5). O resultado pode ser avaliado positivamente, embora sugira que melhorias possam ser realizadas no que se refere à adaptação do Pion ao contexto e às necessidades e preferências do internauta.

Para a questão "Em uma escala que vai de 1 (inexistente) a 5 (muito frequente), como você avalia a ocorrência de erros técnicos e interrupções durante sua navegação pelo Pion?", o ranking médio calculado foi de:

$$
((49 * 1)+(49 * 2)+(17 * 3)+(16 * 4)+(6 * 5)) / 137 \approx 2
$$

O valor do RM está entre o número que indica a inexistência de erros (1) e o que indica uma frequência média (3). Como, nesse caso, há uma inversão no sentido da escala de Likert (quanto menor o valor, melhor o desempenho), o resultado pode, novamente, ser avaliado de forma positiva. E embora haja relato de erros técnicos, estes erros podem ter causas alheias ao sistema estrutural do Pion ou ao servidor que o hospeda - as fontes de erro podem estar nas diversas etapas de transmissão e decodificação de dados, desde o provedor de internet até os softwares utilizados pelo internauta. Uma análise mais detalhada sobre os tipos de erro daria uma melhor dimensão do problema e apontaria caminhos para resoluções.

Para a questão "Em uma escala que vai de 1 (inexistentes) a 5 (totalmente satisfatórias), como você avalia a homogeneidade e a coerência da interface do portal? Leve em conta fatores como denominação, localização, formato, cor e linguagem.", o ranking médio foi de:

$$
((1 * 1)+(7 * 2)+(27 * 3)+(61 * 4)+(41 * 5)) / 137 \approx 4
$$


$\mathrm{O}$ valor do RM está entre o número que indica homogeneidade e coerência médias (3) e o que indica homogeneidade e coerência totalmente satisfatórias (5). Assim, o resultado pode ser visto como positivo, embora melhorias possam ser realizadas.

Para a questão "Em uma escala que vai de 1 (inexistente) a 5 (totalmente satisfatória), como você avalia a correlação direta entre o portal e seu contexto de aplicação? Leve em conta as características do portal e sua compatibilidade com as características dos usuários e das tarefas que estes pretendem realizar.”, o ranking médio calculado foi de:

$$
((2 * 1)+(7 * 2)+(27 * 3)+(57 * 4)+(44 * 5)) / 137 \approx 4
$$

O valor do RM está entre o número que indica uma correlação média (3) e o que indica a correlação totalmente satisfatória (5). Novamente, o resultado pode ser visto como positivo, embora melhorias possam ser realizadas neste quesito.

Todos os sete critérios de avaliação da usabilidade usados na pesquisa tiveram um Ranking Médio próximo do valor ideal.

\section{V.3 Utilização}

A grande proporção de respondentes que acessam o portal menos de uma vez por semana (68\%. Fig. 2) pode ser indicativo de dois fenômenos: o primeiro refere-se ao habitual excesso de carga horária dos professores, o que acaba por reduzir o tempo destinado por estes profissionais para o preparo de aulas e/ou busca por atualizações na área; o outro é uma possível baixa frequência de atualização dos conteúdos do Pion e/ou de divulgação dessas atualizações. Assim, faz-se necessário um estudo mais aprofundado neste caso.

No gráfico da Fig. 3, dois números chamam a atenção: a alta proporção de respondentes que acessam o portal para encontrar informações que auxiliam em atividades escolares (65\%, que inclui professores e estudantes) e a baixa proporção de acessos para postagem de material (1\%). Este último número indica o baixo grau de interatividade com os usuários e pode ser ratificado pelo efetivo envio de material por colaboradores não oficiais ocorrido desde o início do projeto.

Desde que foi aberto à visitação, em fins de 2007, o Pion recebeu, entre livros, apresentações, materiais didáticos, artigos, animações, simulações, jogos, charges e vídeos, cerca de 45 objetos de aprendizagem enviados pelos internautas. 


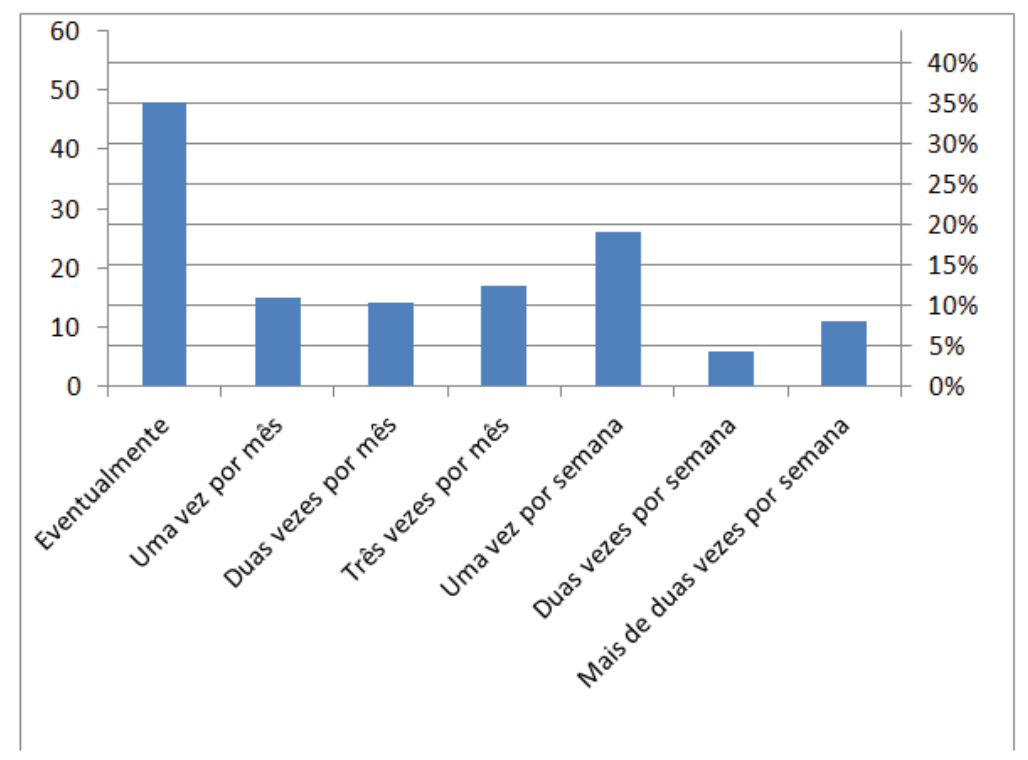

Fig. 2 - Número de respostas à questão: "Com que frequência você acessa o Pion?" $(N=137)$.

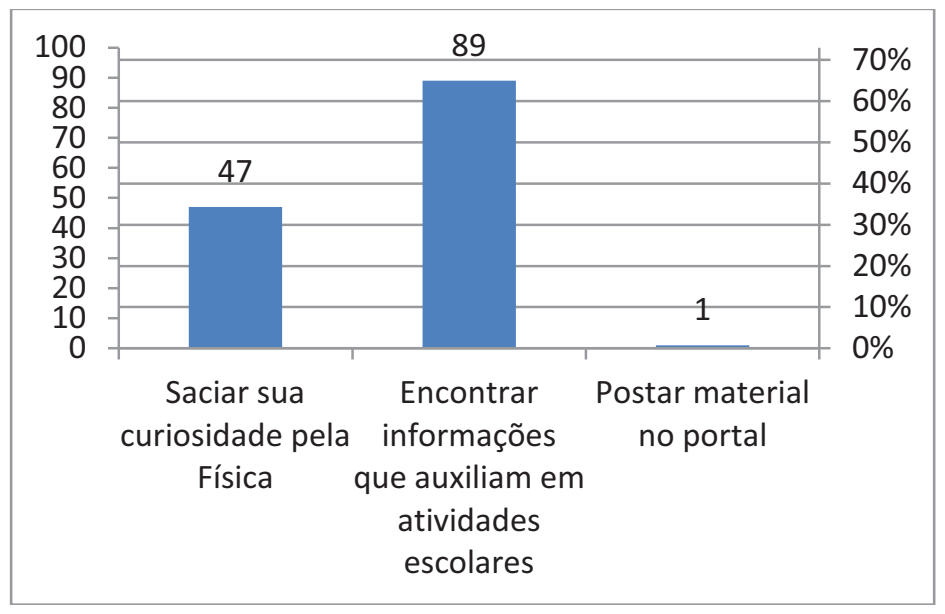

Fig. 3 - Número de respostas à questão: "Com que finalidade, prioritariamente, você acessa o Pion?" $(N=137)$. 
Como comparação, em seu primeiro ano de funcionamento, o Portal do Professor $^{12}$ já havia recebido mais de 3.000 sugestões de aulas (BIELSCHOWSKY; PRATA, 2010). Obviamente, há muitas diferenças entre os dois projetos: em primeiro lugar, apesar de publicar materiais didáticos, o Pion não recebe "sugestões de aulas" — normalmente, adaptações de "planos de aula", documentos comumente arquivados por professores. Outra diferença é com relação ao público alvo: o Pion é dirigido especificamente a professores de Física (eventualmente, de Ciências) enquanto o Portal do Professor é voltado a professores de todos os níveis e todas as áreas, gerando um número muito maior de possíveis visitantes e contribuintes. Finalmente, é importante destacar a dimensão do projeto de desenvolvimento do Portal do MEC, que envolveu secretarias do Ministério da Educação, "secretarias estaduais e municipais de educação representadas pelos coordenadores de programas de TIC nas escolas", "multiplicadores dos Núcleos de Tecnologia Educacional - NTE”, professores, "universidades públicas, por meio de seus institutos, faculdades e colégios de aplicação", "empresas e fundações privadas e públicas", como "Unesco, Fundação Telefônica (Educarede), Bradesco, Vivo, Oi Futuro, Claro, OEI, Cezar, Instituto Algar", "Intel, Corel, Cisco, Adobe, Microsoft; Agência Espacial Brasileira, Embrapa" (BIELSCHOWSKY; PRATA, 2010).

Os materiais mais acessados (material didático, 35\%, e artigo, 34\%. Fig. 4) indicam a grande importância do texto escrito para o portal. Entretanto, a escolha por "Animação / simulação" também teve um valor expressivo (17\%). Vale lembrar, ainda, que as respostas às questões deveriam ser únicas, o que não permitiu a escolha de mais de um tipo de material pelo respondente e significa que muitos internautas que acessam prioritariamente textos também procuram por simulações, vídeos ou outros formatos. O objetivo, aqui, foi o de levantar a prioridade do usuário. Dados mais detalhados de acesso podem ser obtidos com análises de dados estatísticos do portal.

Com relação aos resultados expressos no gráfico da Fig. 5, novamente é preciso atentar ao fato de que as respostas deveriam ser únicas. Assim, prioritariamente, o usuário do Pion acessa materiais sobre "Física e outras áreas da ciência e da tecnologia" (34\%), área seguida por "Física moderna e contemporânea" (24\%).

\footnotetext{
${ }^{12}$ Criado pelo MEC em 2008, o Portal do Professor (<http://portaldoprofessor.mec.gov.br $>$ ) disponibiliza sugestões de aula, reportagens especiais da área da Educação, conteúdos multimídia, informações sobre cursos e materiais de estudo e links de interesse. Além disso, o portal permite a colaboração e a interação do usuário, que pode enviar material ou participar de chats e discussões no fórum.
} 


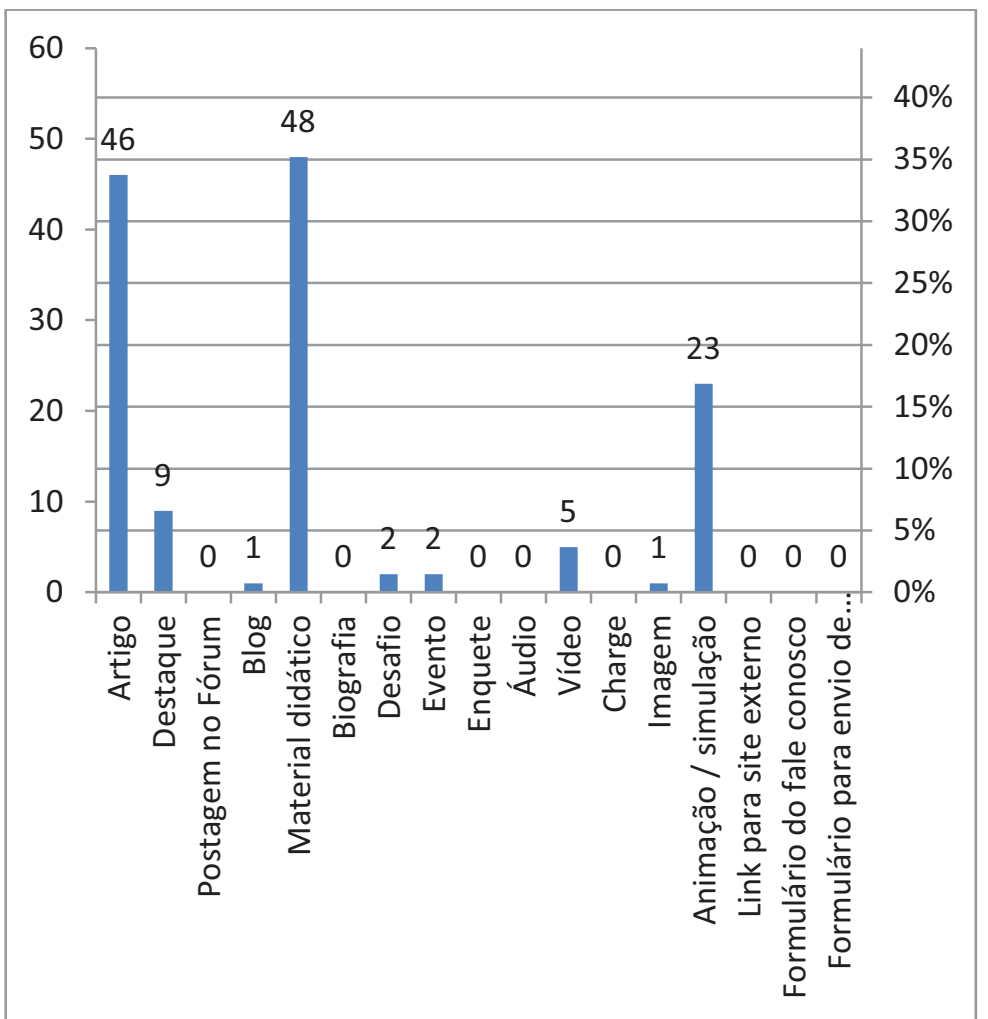

Fig. 4 - Número de respostas à questão: "Qual é o tipo de material mais acessado por você no Pion?" (N=137).

\section{V.4 Satisfação}

Para a questão "Em uma escala que vai de 1 (totalmente insatisfeito) a 5 (totalmente satisfeito), como você se sente, normalmente, ao terminar de acessar o Pion em busca de alguma informação?", o ranking médio calculado foi de:

$((1 * 1)+(4 * 2)+(17 * 3)+(62 * 4)+(53 * 5)) / 137 \approx 4$ 
O valor do RM está muito próximo do número que indica a satisfação total do usuário (5). Este resultado pode ser lido como um reflexo dos altos índices medidos na avaliação da usabilidade do portal.

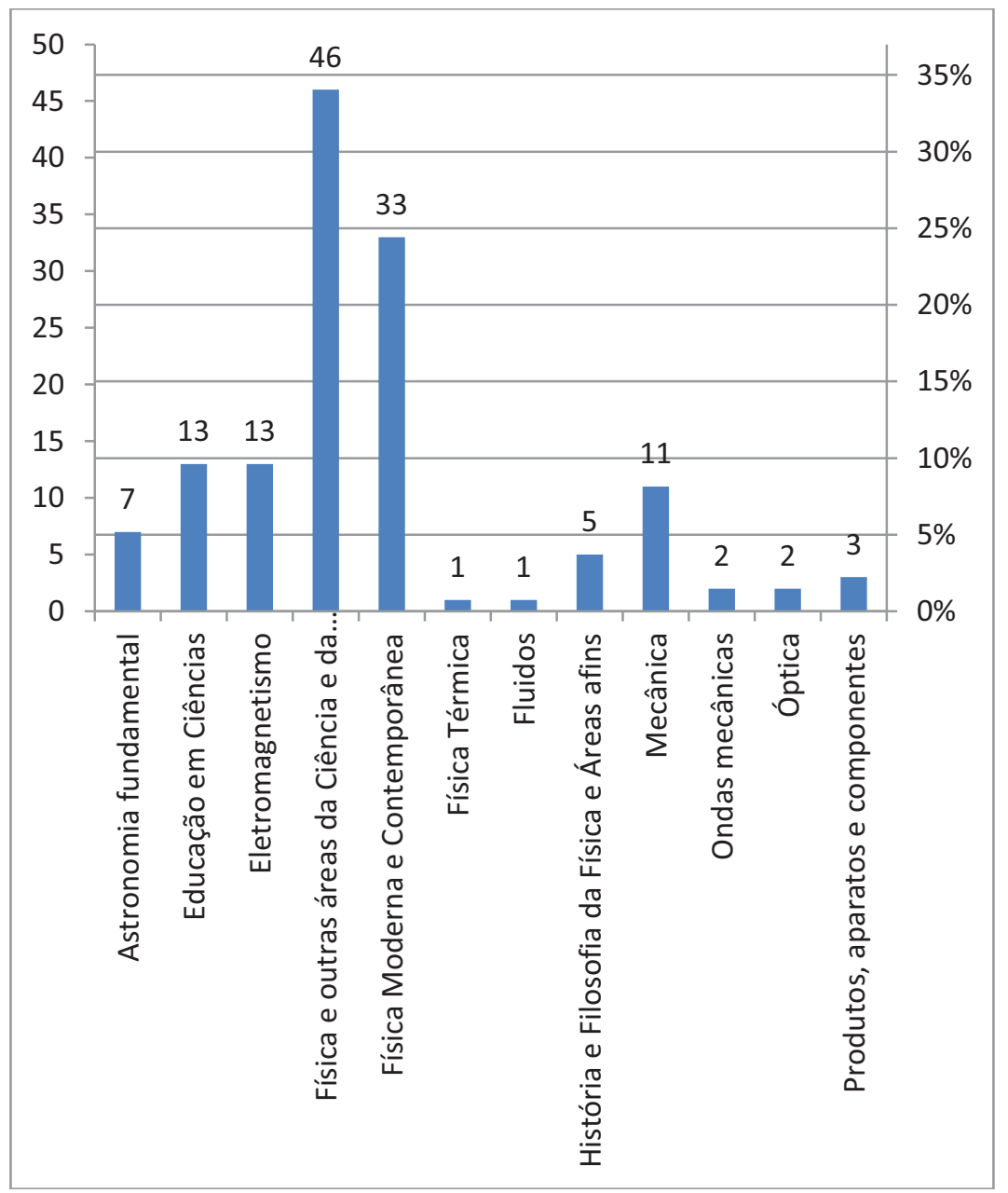

Fig. 5 - Número de respostas à questão: "Qual é a área cujos materiais são mais acessados por você no Pion?" $(N=137)$. 


\section{V.5 Questão aberta}

A grade (tabela 1) e os gráficos abaixo (Fig. 6 e 7) mostram o quantitativo das respostas classificadas segundo as categorias das dimensões de valor e tema.

Para fins de classificação, algumas das 137 respostas foram desmembradas, o que resultou em um total de 163 trechos.

A distribuição das respostas entre as categorias chama a atenção para o grande número de opiniões positivas quanto ao portal de um modo geral (Fig. 6). Este número reflete, mais uma vez, o alto grau de satisfação do usuário com o Pion. Uma grande número de respostas positivas também pode ser observado na categoria 9 (“Apoio ao ensino/professor/aluno").

Tabela 1: Número de trechos de respostas à questão: "Use este espaço para escrever críticas, elogios e sugestões ao Pion.”, classificadas de acordo com categorias das dimensões de valor e tema.

\begin{tabular}{lccc|c}
\hline Categorias & Negativo & Neutro & Positivo & Total \\
\hline 1 :: Fora do escopo & 3 & 5 & 2 & 10 \\
2 :: Geral & 6 & 12 & 58 & 76 \\
3 :: Conteúdo & 18 & 0 & 6 & 24 \\
4 :: Problemas técnicos & 2 & 0 & 0 & 2 \\
5 :: Layout e organização da informação & 4 & 0 & 1 & 5 \\
6 :: Divulgação do Portal & 9 & 0 & 0 & 9 \\
7 :: Interação com/entre professores e & 7 & 0 & 0 & 7 \\
funcionalidades & & & & \\
8 :: Desenvolvimento/divulgação & 1 & 0 & 6 & 7 \\
da ciência & & & & \\
9 :: Apoio ao ensino/professor/aluno & 4 & 0 & 16 & 20 \\
10 :: Linguagem & 2 & 0 & 1 & 3 \\
\hline$\quad$ Total & 56 & 17 & 90 & 163 \\
\hline
\end{tabular}


Os aspectos negativos, por sua vez, são bastante significativos na categoria 3 ("Conteúdo"). Analisando, porém, os trechos classificados nesta categoria, percebe-se que a maior parte deles tem o tom de sugestão, normalmente solicitando a inclusão de determinado tipo de conteúdo no portal. Os 18 trechos classificados como -3 tratam, basicamente, da seção de eventos, de artigos e outros textos, da ampliação do acervo, da seção de desafios, da atualização dos conteúdos e da inserção de assuntos de uma determinada área da física ou do ensino.

\section{Distribuição do número de respostas de acordo com a categoria positivo e as categorias de tema}
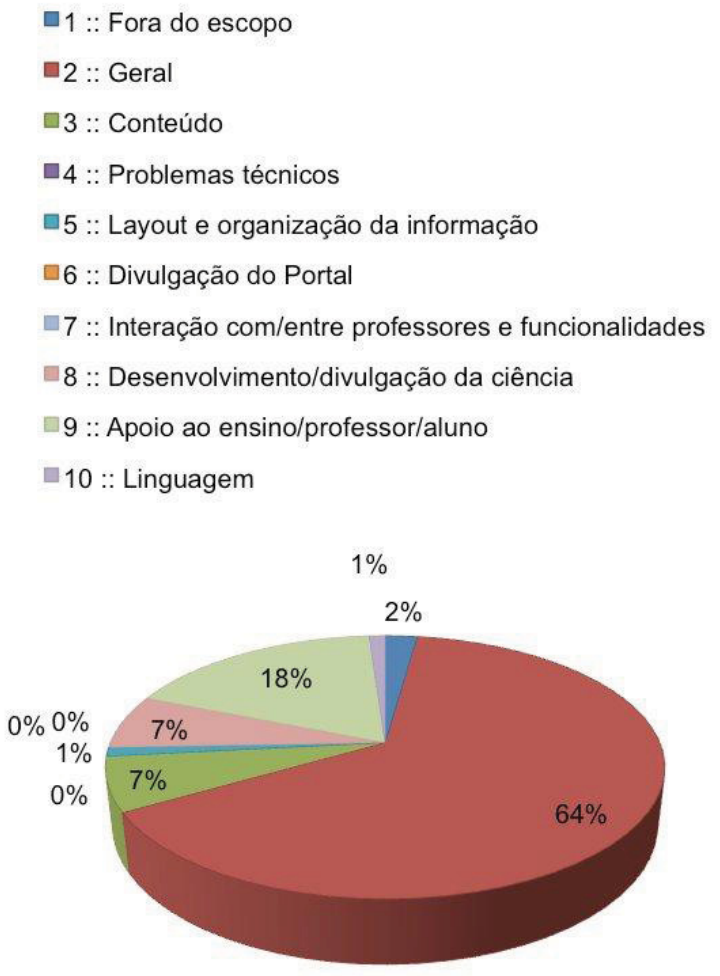

Fig. 6 - Proporção do número de respostas à questão: "Use este espaço para escrever críticas, elogios e sugestões ao Pion.”, classificadas de acordo com a categoria positivo e as categorias de tema. 
Outro aspecto interessante da grade de classificação é o baixo índice de opiniões negativas quanto a problemas técnicos (4) e à adequação de linguagem (10) (Fig. 7). As respostas também mostram um valor significativo de críticas quanto às interações professor/professor e portal/professor (categorias 6 e 7).

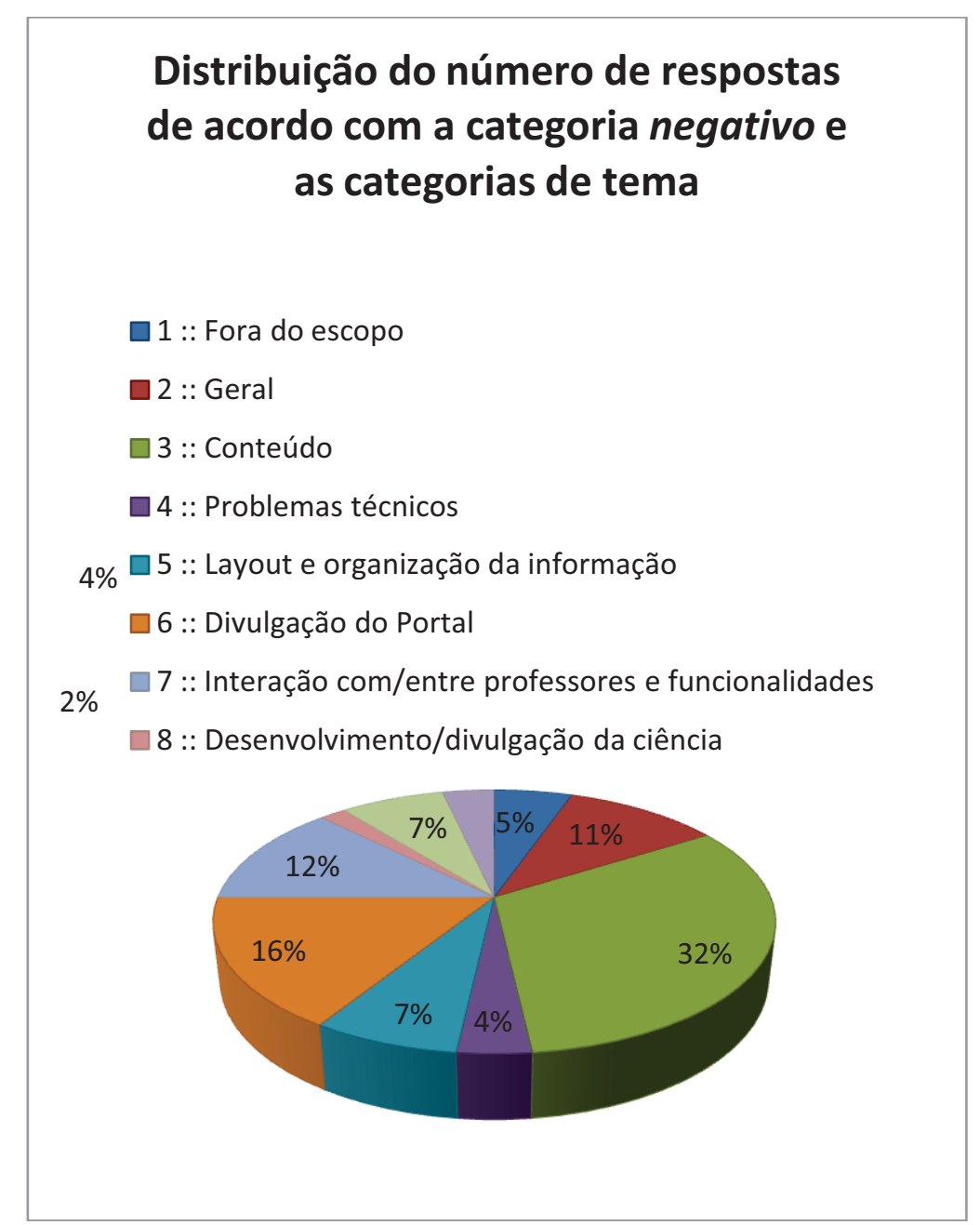

Fig. 7 - Proporção do número de respostas à questão: "Use este espaço para escrever críticas, elogios e sugestões ao Pion. ”, classificadas de acordo com a categoria negativo e as categorias de tema. 


\section{Considerações finais}

De forma geral, as avaliações quanto à usabilidade do Pion foram positivas, permanecendo entre o valor médio e o máximo, o que indica facilidade e rapidez de acesso às informações disponíveis no portal (DIAS, 2001). Como a amostra da pesquisa é formada, em sua maior parte, por docentes, este resultado sugere que o Pion desempenha bem o seu papel de auxiliar o professor no seu trabalho diário, ajudando-o a encontrar material de apoio diante da infinidade de informações na web, orientando-o quanto a assuntos didático-pedagógicos e servindo como fonte de atualização e interação com outros profissionais da área.

O grande número de respostas positivas observado na categoria 9 ("Apoio ao ensino/professor/aluno") da questão aberta reforça essa tese, que responde positivamente a uma das perguntas motivadoras da pesquisa: "o Pion [como um portal que disponibiliza diferentes tipos de OAs de forma seletiva e organizada] auxilia o professor para que este desempenhe o seu papel em sala de aula?".

Quanto à forma como as informações são apresentadas no portal - "os signos utilizados são adequados ao público?" -, pode-se dizer que, de maneira geral, é adequada. As respostas à questão que faz referência à facilidade de leitura e compreensão estão entre a neutralidade e a extrema facilidade de leitura. As respostas à questão aberta que levantaram este assunto mostram, porém, que a aproximação do RM ao número que indica leitura e compreensão "Muito fáceis" não aponta para a existência de redundância nas mensagens.

Quanto ao aspecto da interatividade - "o Pion segue a tendência da Web 2.0? Pode ser considerado uma ferramenta de auxílio à interação social, como a defendida pelo pensador Lev Vygotsky?" -, a pesquisa mostra, entretanto, que o portal ainda apresenta um baixo grau de interatividade com o internauta, como indicam as opiniões negativas classificadas nas categorias "Divulgação do portal" e "Interação com/entre professores e funcionalidades". Essa conclusão é reforçada pela baixa proporção de respostas "Postar material no portal", dadas à questão fechada "Com que finalidade, prioritariamente, você acessa o Pion?".

Analisando o histórico de contribuições para o Pion, constata-se que essa baixa participação não se restringe ao público formado por professores e estudantes. A comunidade de físicos profissionais contribuiu muito pouco e mesmo a Comissão de Ensino da SBF praticamente não se envolveu com o projeto ${ }^{13}$.

${ }^{13}$ Seria injustiça não citar, aqui, alguns nomes que enviaram considerável quantidade de
material e sugestões, principalmente na fase inicial de inserção de conteúdos: os professores 
Vale lembrar que o Pion não permite práticas de programação propriamente dita, como defende Papert (1988). Entretanto, em toda simulação publicada no portal, há certo nível de interatividade que pode ser explorada em sala de aula.

Faz-se necessário, ainda, um comentário sobre a questão "Qual é a área cujos materiais são mais acessados por você no Pion?", em cujas respostas se encontra uma porcentagem significativa (24\%) de opções pela área de Física Moderna e Contemporânea (FMC) - lembrando que se trata de uma questão fechada e que a opção por outras áreas não significa, necessariamente, a negação de materiais sobre FMC.

O resultado mostra que, independentemente do fato de o professor ensinar ou não FMC em suas aulas, ele demonstra interesse em ampliar seus conhecimentos na área, frequentemente negligenciada nos livros didáticos. Há, entretanto, uma tendência de mudança neste quadro. O edital do PNLD - 2012 para o Ensino Médio (BRASIL, 2011) apresenta como um dos critérios eliminatórios para o componente curricular de Física a observação, em cada obra analisada, de tratamento adequado e pertinente,

considerando os diversos estudos presentes na literatura atual da área, tópicos usualmente classificados como de Física Moderna e Contemporânea e que sejam considerados importantes ou mesmo imprescindiveis para o exercício da cidadania ativa, crítica e transformadora, bem como para a inserção ativa, crítica e transformadora no mundo do trabalho.

O assunto já havia sido abordado em uma enquete publicada no Pion, com a questão "Tópicos de física moderna, como noções de TRR e quântica, ficaram de fora do Enem 2009. Você considera essa decisão:". De um total de 566 participantes, $37 \%$ consideraram a decisão "Adequada, pois esse conteúdo, geralmente, é pouco abordado no EM". Por outro lado, $28 \%$ a consideraram "Inadequada, pois um de seus efeitos é a desvalorização desses conteúdos nos currículos". A polarização das respostas ${ }^{14}$ mostra como o problema acabou se transformando em um círculo vicioso, que só pode ser quebrado com a inserção de conteúdos de FMC nos currículos escolares.

Fernando Lang da Silveira (IF-UFRGS), Eliane Angela Veit (IF-UFRGS) e Ildeu de Castro Moreira (IF-UFRJ).

${ }^{14}$ Considerando todas as oito alternativas oferecidas na enquete, exatamente $50 \%$ dos participantes optaram por respostas do tipo "Adequada (...)", enquanto a outra metade julgou a decisão "Inadequada (...)". 
Como professor de Física ${ }^{15}$, fiz e faço uso dos recursos oferecidos pelo Pion, particularmente das simulações e vídeos disponibilizados no portal, sempre com bons resultados em sala de aula. A seção de artigos do Pion traz diversas adaptações jornalísticas de textos publicados originalmente na revista Física na Escola (FnE), publicação da SBF. Estes artigos também são ótimas fontes para novas abordagens educacionais — um dos textos da FnE acessíveis pelo portal, em particular, inspirou a criação de um jogo que venho utilizando em minhas aulas de eletricidade ${ }^{16}$.

Assim como relatado pelo segundo autor (2011) em trecho sobre suas experiências com uso de animações para auxiliar no ensino de tópicos de relatividade, "embora não tenha realizado uma avaliação sistemática do seu uso, os depoimentos pessoais dos estudantes são animadores".

Essa integração entre as funções de editor do portal e de professor de física da Educação Básica acabou por se revelar uma via de mão dupla: de um lado, materiais e artigos postados no Pion auxiliando meu trabalho em sala de aula; de outro, a demanda por novos materiais, percebida na experiência do dia a dia, orientando a busca por objetos de aprendizagem para publicação on-line ${ }^{17}$.

Finalmente, há a sugestão de novas abordagens a serem consideradas em trabalhos semelhantes que visem a melhoras no Pion: comparação das respostas

${ }^{15}$ Professor Educação Básica II na Escola Estadual Léa de Freitas Monteiro, em Araraquara, SP, de 2008 a 2010, e Professor de Ensino Básico, Técnico e Tecnológico, no Instituto Federal de Santa Catarina, em Canoinhas, SC, a partir de 2010

16

O artigo "A física das tempestades e dos raios" (SABA, 2001) foi escrito pelo pesquisador do Inpe Marcelo M. F. Saba em um formato de perguntas e respostas. Isso me permitiu colar cada uma das questões em um cartão numerado que contém em seu verso a resposta a uma outra pergunta. Na sala de aula, distribuo os cartões aleatoriamente para meninos e meninas (caso haja mais meninos do que meninas, por exemplo, algumas garotas ficam com mais de uma carta). Após um tempo para leitura dos cartões, o aluno que está com o cartão número 1 lê a sua pergunta para toda a turma. Quem acha que está com a resposta correta a essa pergunta se manifesta. Caso a resposta seja mesmo a esperada, o grupo correspondente ao gênero de quem responde ganha um ponto. Se a resposta estiver errada, ganha o ponto o outro grupo - além disso, o grupo oposto ao do aluno que estiver com a resposta correta também ganha um ponto. O jogo segue até que todos os cartões tenham sido lidos. É realmente incrível o envolvimento dos estudantes neste tipo de atividade!

${ }^{17}$ A respeito de minhas experiências com tecnologias de informação em sala de aula, vale fazer um registro - mais como uma forma de desabafo - do que talvez seja o maior entrave para o uso desses recursos na educação básica, superando a falta de softwares ou precariedade de hardware: o preconceito, por parte de muitos docentes e profissionais da administração, com relação a algo que não conhecem e temem conhecer. 
sobre a utilização do portal com seus dados estatísticos de acesso; análise de grupos em separado (respostas de estudantes x respostas de professores); busca das possíveis causas de problemas por meio de análise das questões propostas com base nas heurísticas utilizadas (esta análise poderia ser feita por meio de um formulário mais detalhado ou uma análise do portal por um especialista da área ${ }^{18}$ ); elaboração de projeto de implementação de ações sugeridas pelas respostas à questão aberta e suscitadas pela pesquisa como um todo.

\section{Referências bibliográficas}

BARDIN, L. Análise de conteúdo. Lisboa: Edições 70, 1977.

BIELSCHOWSKY, C. E.; PRATA, C. L. Portal Educacional do Professor do Brasil. Revista de Educación, v. 352, mai./ago. 2010.

BRASIL. Ministério da Educação. Edital de convocação para inscrição no processo de avaliação e seleção de obras didáticas para o programa nacional do livro didático PNLD 2012 - Ensino Médio. Brasília, 2011. Disponível em: $<$ http://www.fnde.gov.br/index.php/edital-pnld-2012-ensino-medio $>$. Acesso em: 26 ago. 2011.

DIAS, C. Heurísticas para avaliação de usabilidade de portais corporativos. 2001. Guia elaborado com base na dissertação de mestrado da autora: Métodos de avaliação de usabilidade no contexto de portais corporativos: um estudo de caso no Senado Federal. Brasília: Universidade de Brasília, 2001. 229p.

FLICK, U. Introdução à pesquisa qualitativa. 3. ed. Porto Alegre: Artmed, 2009. $408 \mathrm{p}$.

GUERRA, I. C. Pesquisa qualitativa e análise de conteúdo: sentidos e formas de uso. 1. ed. São João do Estoril, Portugal: Princípia, 2006.

\footnotetext{
${ }^{18}$ Uma primeira leitura dessas heurísticas parece indicar que o Pion obedece à grande maioria das recomendações propostas pela autora, como, por exemplo, "apresentar em destaque o nome da página principal em todas as páginas componentes do portal, preferencialmente no canto superior esquerdo"; "não usar propaganda. Se for necessária, utilizar parte do espaço anteriormente destinado à navegação, e não do espaço destinado ao conteúdo"; "restringir a pesquisa dos serviços de busca apenas ao conteúdo do portal" (DIAS, 2001), etc.
} 
HAGUENAUER, C. J. et al. Portais de informação e Comunidades Virtuais de Aprendizagem: o Caso do Portal Dinos Virtuais. Revista EducaOn-line, v. 1, n. 3, set./dez. 2007. Disponível em:

$<$ http://www.latec.ufrj.br/revistaeducaon-line/vol1_3/1_portaisedinos.pdf $>$. Acesso em: 23 jun. 2011.

HEURÍSTICA (COMPUTAÇÃO). In: WIKIPÉDIA, a enciclopédia livre. Flórida: Wikimedia Foundation, 2011. Disponível em:

$<$ http://pt.wikipedia.org/w/index.php?title=Heur\%C3\%ADstica_(computa\%C3\%A 7\%C3\%A3o)\&oldid=24784632>. Acesso em: 31 out. 2011.

ISONTANI, S. et. al. Estado da arte em web semântica e web 2.0: potencialidades e tendências da nova geração de ambientes de ensino na internet. Revista Brasileira de Informática na Educação, v. 17, n. 1, 2009. Disponível em: $<$ http://www.br-ie.org/pub/index.php/rbie/article/viewFile/4/4>. Acesso em: 25 jun. 2011.

LITTLE JOHN, S. W. Fundamentos teóricos da comunicação humana. Rio de Janeiro: Zahar, 1982.

MALHOTRA, N. K. Pesquisa de marketing: uma orientação aplicada. 3. ed. Porto Alegre: Bookman, 2001.

OLIVEIRA, L. H. Exemplo de cálculo de Ranking Médio para Likert. Notas de Aula. Metodologia Científica e Técnicas de Pesquisa em Administração. Mestrado em Adm. e Desenvolvimento Organizacional. PPGA CNEC/FACECA: Varginha, 2005 .

PAPERT, S. LOGO: Computadores e educação. 3. ed. São Paulo: Editora Brasiliense, 1988.

PASSERINO, L. M.; SANTAROSA, L. M. C. A interação social em ambientes telemáticos. Revista Informática na Educação: Teoria \& Prática, Porto Alegre, v. 5, n. 2, nov. 2002. Disponível em:

$<$ http://seer.ufrgs.br/InfEducTeoriaPratica/article/view/5274/3484>. Acesso em: 20 mar. 2011.

SABA, M. M. F. A física das tempestades e dos raios. Revista Física na Escola, v. 2, n. 1, 2001. Disponível em:

$<$ http://www.sbfisica.org.br/fne/Vol2/Num1/raios.pdf >. Acesso em: 31 out. 2011. 
STUDART, N. Objetos de aprendizagem no ensino de Física: um recurso pedagógico moderno para professores e alunos. E-book 1, p. 39. In: REUNIÃO DA ANPED SUDESTE, 2011, Rio. Disponível em:

$<$ http://www.fe.ufrj.br/anpedinha2011/ebooks.html>. Acesso em: 20 ago. 2011.

TEIXEIRA, R. R. P; JÚNIOR, M. P; GOLFETTE, B. H. Perfil dos professores de física do ensino médio em São Paulo. 2004. Disponível em:

$<$ http://ufpa.br/ensinofts/perfilpfsp.html>. Acesso em: 30 out. 2011.

VILELLA, R. M. Conteúdo, usabilidade e funcionalidade: três dimensões para avaliação de portais estaduais de governo eletrônico na web. 2003. Dissertação (Mestrado em Ciência da Informação) - Universidade Federal de Minas Gerais, Belo Horizonte, MG.

VYGOTSKY, L. S. A formação social da mente. 4. ed. São Paulo: Livraria Martins Fontes Editora Ltda, 1991.

\section{Anexo A: Questões para formulário on-line}

\section{Perfil do internauta}

1.1 Nome

1.2 Sexo

[ ( ) Masculino

( ) Feminino ]

1.3. Idade

[Abre Lista]

1.4. Cidade

1.5. Estado

[Abre lista]

1.6. E-mail

1.7. Ocupação

[ ( ) Professor de Ciências do Ensino Fundamental

( ) Professor de Física do Ensino Médio

( ) Professor de Física do Ensino Técnico 
( ) Professor de Física do Ensino Superior

( ) Estudante do Ensino Fundamental

() Estudante do Ensino Médio

( ) Estudante do Ensino Técnico

() Estudante do Ensino Superior

() Outro. Qual? ]

\section{Usabilidade}

2.1. Em uma escala que vai de 1 (totalmente ineficazes) a 5 (totalmente eficazes), como você avalia as orientações presentes no Pion com relação à página em que você se encontra, ao caminho que o levou até esta página e às suas opções de saída - links, menus, títulos etc.?
[ ( ) 1
( ) 2
( ) 3
( ) 4
( ) 5 ]

2.2. Em uma escala que vai de 1 (muito difíceis) a 5 (muito fáceis), como você avalia a leitura e a compreensão do conteúdo disponível no Pion? Leve em conta a legibilidade, a estética e a quantidade de informação por página.
[ ( ) 1
() 2
( ) 3
() 4
( ) 5 ]

2.3. Em uma escala que vai de 1 (totalmente insatisfeito) a 5 (totalmente satisfeito), como você avalia sua satisfação com relação ao controle detido por você sobre o processamento de suas ações pelo portal, levando em conta o atendimento a suas solicitações e expectativas?
[ ( ) 1
() 2
( ) 3
() 4
( ) 5 ] 
2.4. Em uma escala que vai de 1 (inexistente) a 5 (muito grande), como você avalia a capacidade do Pion em se adaptar ao contexto e às necessidades e preferências do internauta, em função da diversidade de tipos de usuários do portal? Leve em conta a flexibilidade de sua interface para a realização da mesma tarefa de diferentes maneiras.

[ ( ) 1

() 2

() 3

() 4

( ) 5 ]

2.5. Em uma escala que vai de 1 (inexistente) a 5 (muito frequente), como você avalia a ocorrência de erros técnicos e interrupções durante sua navegação pelo Pion?

[ ( ) 1

() 2

() 3

() 4

( ) 5 ]

2.6. Em uma escala que vai de 1 (inexistentes) a 5 (totalmente satisfatórias), como você avalia a homogeneidade e a coerência da interface do portal? Leve em conta fatores como denominação, localização, formato, cor e linguagem.

[ ( ) 1

() 2

() 3

() 4

() 5 ]

2.7. Em uma escala que vai de 1 (inexistente) a 5 (totalmente satisfatória), como você avalia a correlação direta entre o portal e seu contexto de aplicação? Leve em conta as características do portal e sua compatibilidade com as características dos usuários e das tarefas que estes pretendem realizar.

[ ( ) 1

() 2

() 3

() 4

( ) 5 ] 


\section{Utilização}

3.1. Com que frequência você acessa o Pion?

[ ( ) Eventualmente

( ) Uma vez por mês

( ) Duas vezes por mês

( ) Três vezes por mês

( ) Uma vez por semana

( ) Duas vezes por semana

( ) Mais de duas vezes por semana ]

3.2. Com que finalidade, prioritariamente, você acessa o Pion?

[ ( ) Saciar sua curiosidade pela Física

( ) Encontrar informações que auxiliam em atividades escolares

( ) Postar material no portal ]

3.3. Qual é o tipo de material mais acessado por você no Pion?

[ ( ) Artigo

( ) Destaque

( ) Postagem no Fórum

( ) $B \log$

( ) Material didático

( ) Biografia

( ) Desafio

( ) Evento

() Enquete

( ) Áudio

( ) Vídeo

( ) Charge

( ) Imagem

( ) Animação / simulação

( ) Link para site externo

( ) Formulário do fale conosco

( ) Formulário para envio de material ]

3.4. Qual é a área cujos materiais são mais acessados por você no Pion?

[ ( ) Astronomia fundamental

( ) Educação em Ciências

( ) Eletromagnetismo 
( ) Física e outras áreas da Ciência e da Tecnologia

( ) Física Moderna e Contemporânea

( ) Física Térmica

( ) Fluidos

( ) História e Filosofia da Física e Áreas afins

( ) Mecânica

( ) Ondas mecânicas

() Óptica

( ) Produtos, aparatos e componentes ]

\section{Satisfação}

4.1. Em uma escala que vai de 1 (totalmente insatisfeito) a 5 (totalmente satisfeito), como você se sente, normalmente, ao terminar de acessar o Pion em busca de alguma informação?

[ ( ) 1

() 2

() 3

() 4

( ) 5 ]

\section{5. Questão aberta}

5.1. Use este espaço para escrever críticas, elogios e sugestões ao Pion. 